\title{
Immunological and Mathematical Variations in Migraineous Patients
}

\author{
Reena Mittal ${ }^{1}$, Pakhi Mittal ${ }^{2,3}$ and Sanjeev Kumar ${ }^{4 *}$ \\ ${ }^{1}$ Department of Physics, Medical Physics Research Laboratory, DAV (PG) College, India \\ ${ }^{2}$ Department of Mathematics, Shri K K Jain College, India \\ ${ }^{3}$ Department of Mathematics, Shri Ganesh Shankar Vidhyarti Memorial Medical College, India \\ ${ }^{*}$ Department of Physics, Medical Physics Research Laboratory, DAV (PG) College, India
}

Received: 阱 February 26, 2018; Published: 觜 March 06, 2018

*Corresponding author: Dr. Sanjeev Kumar, Associate Professor in Physics, Patel Nagar, Muzaffar Nagar, India, Tel: 09634996303;

Email: sanjeev1962kumar@rediffmail.com

\begin{abstract}
In the present work we have used some of the most clinically important and tested techniques Radial immuno diffusion to the study the disease which is Migraine. we have estimated the immunological Parameters. It is very interesting that the levels of IgG are higher in comparison to the healthy person. Statistical methods were applied to test the significance of the data at 0.05 percent level of significance. Regression lines were also made to see the effect of one parameter on the others. A clear cut differentiation was found in the immunological variations. The mean values and standard deviation in normal is found (17.24 \pm 17.69$) \mathrm{g} / \mathrm{l}$, while in migraineous patients was higher and equal to $(19.59 \pm 22.75) \mathrm{g} / \mathrm{l}$
\end{abstract}

Keywords: Migraine; Immunological parameters; Regression lines

Abbreviations: BNP: Pro-Brain Natriuretic Peptide; IgE: Immunoglobulin E

\section{Introduction}

Migraine is not just a bad headache. It is a collection of neurological symptoms which includes a severe recurring intense throbbing pain on one side of the head. It has been seen that one third of migraine attacks in which both sides of the head are attacked. Migraine is a syndrome. we may call it as a collection of symptoms, which arise from a common cause. The syndrome may occur in a complete form with all of the typical symptoms, in a less complete form, with some symptoms, or in specific groupings of symptoms. Migraine may be classified according to the grouping of its symptoms. The symptoms vary widely and migraine is generally misdiagnosed. Migraine is a moving target. Carlos $\mathrm{M}$ et al. [1] have studied food allergy mediated by IgG antibodies associated with Migraine in adults. They have also mentioned that eighteen percent of women and six percent of the men have migraine. Many years ago, the association of pain and inflammation with definite clinical signs forced the general physician to suspect a connection between the immunological mechanism and headaches or migraine.
Migraine is a painful disease which affects a significant portion of the adult population with a substantial economic burden on the society. Migraine disorder is characterized by recurrent unilateral headaches, which accompanied by nausea, vomiting, photophobia or photophobia. Julio P et al. [2] have studied IgG-mediated allergy with a new mechanism for migraine attacks and mentioned that with the advancement of neuro imaging and genetic techniques. The patho physiology of migraine has not been completely filterated and clarified. Sodium cromaglycate exerted a protective effect which provide a food allergy reaction is the main trigger of migraine. Main problem is to accept the dietary hypothesis is the lack of clear scientific explanation of the mechanisms implicated in the advancement of migraine attacks which are precipitated by food. Authors have also observed that mechanisms is an allergy mediated by IgE antibodies. The interaction of a food constituents with a specific IgE antibody would produce a response by activation of component or degranulation of mast cells. Many scientists were 
failed to find out the elevated IgE levels or complement activation during migraine attack. Diet sensitive patients are sensitive to several different types of foods. Some findings are suggesting the amine hypothesis, which is a clinical challenge to test tyramine or ß-phenyl ethylamine.

Mesut C et al. [3] have studied migraine and immunoglobulin E-mediated hypersensitivity and found that atopic disease may occur frequently in patients with migraine and IgE levels in patients with migraine may be higher than the levels observed during interictal period. Several attacks are associated frequently with higher IgE levels during migraine attacks. Pilarska E et al. [4] have studied anti phospholipid antibodies in children with migraine and reported that the occurrence and the role of anti cardiolip in antibodies in children with migraine. Authors clearly evaluated and found that the higher values of the anti cardiolipin antibody in comparison to control group of the children. Schimomura T et al. [5] have studied immunoglobulin Kappa/Lambda ratios in migraine and tension type headache and reported that the serum kappa and lambda levels of immunoglobulins were higher than the control group of persons. The Kappa /Lambda ratios of IgA and IgM in the patients with headache were higher than those in the controls. The total concentrations of all the three immunoglobulis IgA, IgG and IgM were significantly higher in the migraineous patients. Authors have also suggested that immunological system activation might exist. It may be related to the aetiology of tension type headache and migraine.

Blakan S et al. [6] have studied immunoglobulin and complement levels in migraine. Authors have reported that serum levels of IgG, IgA, IgM and $c_{3}$ of migraineous patients were found to be increased realistically when compared with the control group. Munno I et al. [7] have studied immunological aspects in migraine: increase of IL-10 plasma levels during attack. Authors have reported that monitoring of 23 patients with migraine without aura during a migraine attack. The plasma levels of interleukin (IL-4,IL5,IL-10) and interferon -gamma were low to undetectable IL-5 and IL-4 levels. A higher IL-10 were found in some patients. Interferon -gamma plasma were not detectable in all patients. Antoni J et al. [8] have studied immunoglobulins and complements in migraine and found that $c_{3}$ levels were decreased $c_{4}$ levels were in the normal group. Immunoglobulin levels did not show any statistically significant changes in the patients. IgA levels were lowered in the migraine patients. These alterations in the patients can lead to the statement that the alternative pathway of complement system may be activated in migraine.

Gazerani P et al. [9] have studied a correlation between migraine, histamine and immunoglobulin e and measured the serum total IgE and histamine levels and reported that serum histamine $(\mathrm{mg} / \mathrm{ml})$ in controls were $(48.16 \pm 2.70) \mathrm{mg} / \mathrm{ml}$ and $(38.31 \pm 3.20) \mathrm{mg} / \mathrm{ml}$ in migraine patients. It has been also measured in the case of migraine with allergy group as (159.11 $\pm 4.60) \mathrm{IU} / \mathrm{ml}$ and $(303.30 \pm 42.50) \mathrm{IU} / \mathrm{ml}$ and in the migraine without allergy group $(105.01 \pm 8.50) \mathrm{IU} / \mathrm{ml}$ and $(79.07 \pm 2.70)$ $\mathrm{IU} / \mathrm{ml}$. The authors finally concluded that the avoidance of allergic conditions in migraine patients may be a very easy, helpful way for prophylaxis or their treatment. Nattero G et al. [10] have studied serum complement and immunoglobulins in patients with common migraine and found that no complement activation or variation in the immunoglobulin of migraine sufferers during healthy intervals and migraine attacks that in any way support an involvement of the immune system in the pathogenesis of common migraine. Moore TL et al. [11] have studied immunoglobulin, complement and immune complex levels during a migraine attack and found that the value of IgG in migraine patients as $(1,344 \pm 00) \mathrm{mg} / \mathrm{dl}$, while in headache free cases it was $(1,394 \pm 00) \mathrm{mg} / \mathrm{dl}$. The value of IgM in migraine was estimated(141 \pm 00$) \mathrm{mg} / \mathrm{dl}$ and in headache free cases was $(144 \pm 00) \mathrm{mg} / \mathrm{dl}$. The value of IgA in migraine cases was $(142 \pm 00) \mathrm{mg} / \mathrm{dl}$ and in headache free cases it was $(143 \pm 00) \mathrm{mg} /$ $\mathrm{dl}$. They have also measured the complements $\mathrm{c}_{3}$ and $\mathrm{c}_{4}$. The value of $c_{3}$ in migraine patients was $(164 \pm 00) \mathrm{mg} / \mathrm{dl}$, while in headache free cases was found $(165 \pm 00) \mathrm{mg} / \mathrm{dl}$. The value of complement c4 in migraine was ( $26 \pm 00) \mathrm{mg} / \mathrm{dl}$ and in headache free cases was $(27.5 \pm 00) \mathrm{mg} / \mathrm{dl}$. They have also estimated immune complexes with frequency of $(40 \pm 20) \mu \mathrm{g} / \mathrm{ml}$ and it was $(36 \pm 00) \mu \mathrm{g} / \mathrm{ml}$ in migraine and $(36 \pm 00)$ headache free cases.

Dzugan SA et al. [12] have studied and reported that is migraine a consequence of a loss of neurohormonal and metabolic integrity ? A new hypothesis. Authors have mentioned that migraine most commonly strikes woman. Each person who suffers from migraine is special and unique. Treatment to individuals is very complex and may be varied. There is no specific single treatment methodology is given in the literature. Recent treatments for migraine include diet changes, stress management, proper sleep, HRT, supplements and prescription drugs. During migraine attack cerebral blood vessels go through a period of constriction and dilation. Imbalance in brain biochemistry may be the cause of this change. Menstrual migraine shows a model that fits perfectly with a neuroendocrine hypothesis which is completely based upon a faulty chronological response of the antinociceptive system. Authors have mentioned the work of $[13,14]$ has studied the effects of hormone imbalances and deficiencies on vasomotor control were significant clinically and hormone treatment was effective in the management of a variety of conditions due to the abnormal blood flow, including migraine. Diamond S et al. [15] have studied estrogens exert their influence by modulating sympathetic control of cerebral vasculature.

Migraine attacks occur during menses in sixty percent of woman and appear to be related to the with drawl of estrogen. The fluctuations in estrogen levels associated with migraine produce some biochemical changes in prostaglandins production, prolactin release, and opioid regulation. An elevation of estrogen increase sodium retention which is a case of interstitinal fluid retention and edema. A change of hormone can be primary case of migraine initiation and a changed peripheral nervous system can be useful 
in initiating secondary change of hormonal balance [16]. Have given an idea regarding this disease and reported that migraine is a recurrent clinical syndrome characterized by combinations of neurological, gastro intestinal and autoimmune manifestation. Migraine is a complex disorder including malfunctions in a few systems: neurohormonal system which includes feedback loop mechanism between hypothalamus, pituitary gland which produce steroid hormones : sympathetic, parasympathetic system ; calcium/ magnesium ions system, pineal gland system and digestive system. All these changes have a very close interrelationship and each of them can be a trigger mechanism for migraine.

Uzar E et al. [17] have studied serum cytokine and pro-brain natriuretic peptide (BNP) levels in patients with migraine. Authors have given an extensive explanation for migraineous patients, these patients have higher IL-1ß,IL-6 levels and pro-BNP and lower IL10 levels than healthy individuals. The cytokines may be related to the pathogenesis of migraine. Tietjen G F [18] reported that role of the vasculature in patients with migraine is increasing because of growing evidence that migraine is a risk factor for clinical and subclinical brain is chaemia, as well as for more wide spread vascular changes. The vasculopathy of migraine is associated with endothelial dysfunction. It is a disorder of endothelial activation and impared vascular reactivity, which is a risk factor of all vascular events. Lord GDA et al. [19] have been studied immunoglobulins and complements in migraine and found that elevated immunoglobulin levels and complement activation suggest a late onset immune reaction of short duration. Such a mechanism provides an explanation of many of the features of non prodromal migraine, platelet release of serotonin, basophil and mast cell degranulation, increased whole blood histamine during an attack, fluid retention, increased thrombotic tendency and increased CSF lactate and GABA.

Pascol J et al. [20] have studied a woman with daily headache and found that dietary factors must be specifically examined into migraine patients particularly in those cases with frequent attacks and no evidence of analgesic abuse or psychiatric comorbidity. Merrett J et al. [21] have studied food related antibodies in headache patients and reinvestigated the role of IgE mediated food allergy in migraine by using a highly sensitive IgE RAST technique to determine circulating levels of specific IgE to four foods commonly supposed to trigger migraine. Specific $\operatorname{IgG}_{4}$ levels were also examined. Authors have also seen that it is responsible for the late response in some cases of asthma. Arrovave Hernandez CM et al. [22] have studied food allergy mediated by IgG antibodies associated with migraine in adults and found that the elimination diets successfully can control the migraine without the need of medication. Authors also suggested that need of medications. Authors also suggested that serum IgG antibodies to common food should be investigated in patients with migraine.

Rusario D et al. [23] have studied role of gender and serum immunoglobulin E(IgE) levels on severity of migraine.Authors have pointed out that migraine headache is a common disorder. Several studies have revealed that migraine headache is more common in patients with allergy. Atopy, which is the genetic pre disposition to develop IgE antibodies to specific allergens, may be associated with increased frequency of migraine headache. Authors have also reported that younger age and female sex are contributory factors as prevalence of both allergic rhenititis and migraine is higher in these groups. Degrees of allergic sensitization determined the severity and frequency of headache in those whom allergy is a risk factor as evidenced by higher levels of IgE. Aydinlar EI et al. [24] have studied IgG based elimination diet in migraine plus irritable bowl syndrome and reported that food elimination based on IgG antibodies in migraine patients who suffers from concomitant IBS may effectively reduce symptoms from both disorders with potential savings to the health care system.

It would be have been possible to check whether the IgG response correlated with diet by a second IgG measuremenet after elimination or provocation. The use of a specific diet rather than an universal migraine diet with simultaneous elimination opf all known dietary triggers seems to provide a well balanced diet in terms of safety and nutritional reasons. Some of the authors $[25,26]$ have put forward their thoughts that migraine is a chronic neuromuscular disorder, characterized by episodic and disabiling headaches with autoimmune symptoms. There is a growing body of evidence to suggest that migraine and inflammation are linked, and often the term neurogenic inflammation is used. Yimaz IA et al. [27] have reported that epidemiological evidence suggests that migraine is not only affected to neurovascular involvement but also other vascular involvements. Some of the authors [27-29] have reported that physiologic profile of migraine involves the neurovascular system, and population -based studies have related migraine with a higher prevalence of cardiovascular risk score for coronary heart disease. Migraine has been associated with increased risk of ischemic stroke and ischemic heart disease. The pro-brain nateriuretic peptide (pro-BNP) reflects an integral or risk factors resulting in the current functional cardiovascular states of individual patients. Pro-BNP is a cardiac neurohormone specifically secreted from the ventricles in response to volume expansion and pressure overload.

Pro-BNP inhibits the sympathetic nervous system and the activities of several other hormone system, including the renninangiotensin -addosterone system. Tietjen GE [18] studied the role of vasculature in patients with migraine is increasing because of growing evidence that migraine is a risk factor for clinical and subclinical brain ischemia, as well as for nerve more wide spread vascular changes. The vasculopathy of migraine is associated with endothelial dysfunction, a disorder of endothelial activation and impaired vascular reactivity which is a risk factor for all vascular events. Dalesio DJ [30] reported that migraine attack is a complex process that involves both the cerebral and peripheral structures. Migraine is under the control of multiple factors: neurogenic, 
chemical, metabolic and myogenic. It is generally accepted that migraine is caused by a primary biochemical disorder of the central nervous system involving neurotransmitters, specificically serotonin. The immunological parameters (IgA, IgG, IgM, $C_{3}$ \& $\mathrm{C}_{4}$ ) were quantitied by using singles radial immunodiffusion method of Mancini et al. [31] using commercially available antibody-agar plates. The plates were standardized with purified immunoglobulins.

\section{Materials and Methods}

Blood sample of Migraine patients along with normal healthy control were collected from the Department of Neurology,
Safdarjang Hospital, New Delhi-110016 after the approval of ethical committee of the hospital. $10 \mathrm{ml}$ freshly drawn blood from each patient was collected in clean and dry test tube without any anti-coagulant. The test tube was kept for 45 minutes at room temperature $(22 \pm 20 \mathrm{C})$ for the formation of clot. Sera of different patients were separated by centrifugation at 1500 r.p.m. upto 15 minutes and were collected in screw capped test tubes.

\section{Results}

We have measured the values of in Migraine patients and healthy normal control given in Table 1. $\mathrm{p}$ value, $\mathrm{t}$ value and regressions equations for migraine and controls are given in the Table 2-5.

Table 1: Mean and standard deviation of all the immunological parameters are given.

\begin{tabular}{|c|c|c|c|}
\hline S.No & Type of samples & Experimental findings Mean \pm SD & Diagnosis \\
\hline \multirow{2}{*}{1.} & \multirow{2}{*}{$\mathrm{C}_{3}$} & $(1.55 \pm 1.3) \mathrm{g} / \mathrm{l}$ & Migraine \\
\hline & & $(1.571 .71) \mathrm{g} / \mathrm{l}$ & Control \\
\hline \multirow{2}{*}{2} & \multirow{2}{*}{$\mathrm{C}_{4}$} & $(0.252 \pm 0.11) \mathrm{g} / \mathrm{l}$ & Migraine \\
\hline & & $(0.27 \pm 0.44) \mathrm{g} / \mathrm{l}$ & Control \\
\hline \multirow{2}{*}{3} & \multirow{2}{*}{ IgG } & $(19.59 \pm 22.75) \mathrm{g} / \mathrm{l}$ & Migraine \\
\hline & & $(17.24 \pm 17.69) \mathrm{g} / \mathrm{l}$ & Control \\
\hline \multirow{2}{*}{4} & \multirow{2}{*}{ IgM } & $(1.386 \pm 1.58) \mathrm{g} / \mathrm{l}$ & Migraine \\
\hline & & $(2.42 \pm 1.16) \mathrm{g} / \mathrm{l}$ & Control \\
\hline \multirow{2}{*}{5} & \multirow{2}{*}{$\operatorname{IgA}$} & $(2.23 \pm 4.15) \mathrm{g} / \mathrm{l}$ & Migraine \\
\hline & & $(2.82 \pm 1.95) \mathrm{g} / \mathrm{l}$ & Control \\
\hline
\end{tabular}

Table 2: $\mathrm{p}$ value of the immunological parameters are given.

\begin{tabular}{|c|c|c|c|c|}
\hline S.N. & Parameter & P value & Two tailed or one tailed & Significant or not significant at $\mathbf{P}<\mathbf{0 . 0 5}$ \\
\hline 1 & IgA & 0.061073 & One tailed & Not significant \\
\hline 2 & IgG & 0.1122 & One tailed & Not significant \\
\hline 3 & IgM & 0.013908 & One tailed & Not significant \\
\hline 4 & C3 & 0.42715 & One tailed & Not significant \\
\hline 5 & C4 & 0.346985 & One tailed & \\
\hline
\end{tabular}

Table 3: $\mathrm{t}$ value of the immunological parameters are given.

\begin{tabular}{|c|c|c|c|c|}
\hline S.N. & Parameter & t value & Two tailed or one tailed & Significant or not significant at $\mathbf{~}<\mathbf{0 . 0 5}$ \\
\hline 1 & IgA & 1.614221 & One tailed & Not significant \\
\hline 2 & IgG & 1.249646 & One tailed & Not significant \\
\hline 3 & IgM & 2.355692 & One tailed & Not significant \\
\hline 4 & C3 & 0.815806 & One tailed & Not significant \\
\hline 5 & C4 & 0.398674 & One tailed & \\
\hline
\end{tabular}

Table 4: Regresssion equations of the immunological parameters for migraine are given.

\begin{tabular}{|c|c|}
\hline S.N & Regrssion lines for migraine \\
\hline 1 & $C_{4}=-1.132858119 \cdot 10^{-2} \operatorname{IgA}-7.831606037 \cdot 10^{-3} \operatorname{IgG}-1.515137283 \bullet 10^{-2} \mathrm{IgM}-.120547452 \cdot 10^{-2} \mathrm{C} 3+0.562269946$ \\
\hline 2 & $\operatorname{IgA}=1.282348795 \cdot 10^{-1} \operatorname{IgG}+3.356121809 \cdot 10^{-2} \mathrm{IgM}-1.117464107 \mathrm{C}_{3}-0.612030393 C_{4}+1.5625583$ \\
\hline 3 & $\operatorname{IgG}=4.594746032 \cdot 10-1 \operatorname{IgM}+2.933867999 C_{3}-8.305643753 C_{4}+2.517277923 \operatorname{Ig} A+10.87297372$ \\
\hline 4 & $\operatorname{IgM}=-0.39363697 C_{3}-1.593492121 \bullet 10-1 C_{4}+6.533383965 \cdot 10^{-3} \operatorname{IgA}+4.556558811 \bullet 10^{-3} \operatorname{IgG}+1.93349447$ \\
\hline 5 & $C_{3}=-0.449838766 C_{4}-1.306711185 \cdot 10^{-1} \operatorname{IgA}+1.747678717 \cdot 10^{-2} \operatorname{IgG}-2.364511563 \bullet 10^{-1} \operatorname{IgM}+1.943023363$ \\
\hline
\end{tabular}


Table 5: Regression equations of the immunological parameters for control are given.

\begin{tabular}{|c|c|}
\hline S.N & Regression lines for controls \\
\hline 1 & $\mathrm{C}_{4}=-1.069983219 \bullet 10^{-1} \mathrm{IgA}-8.501646232 \cdot 10^{-3} \mathrm{IgG}+1.232850397 \bullet 10^{-2} \mathrm{IgM}+8.189429389 \bullet 10^{-2} \mathrm{C}_{3}+5.624035427 \bullet 10-1$ \\
\hline 2 & $\mathrm{IgA}=-2.571470316 \bullet 10-2 \mathrm{IgG}+1.289787397 \bullet 10^{-1} \mathrm{IgM}+6.095298288 \bullet 10^{-1} \mathrm{C}_{3}-4.253270112 \mathrm{C}_{4}+3.155431848$ \\
\hline 3 & $\mathrm{IgG}=8.641533297 \bullet 10^{-1} \mathrm{IgM}+2.224676019 \mathrm{C}_{3}-11.26048115 \mathrm{C}_{4}-8.568196862 \bullet 10^{-1} \mathrm{IgA}+17.13427846$ \\
\hline 4 & $\mathrm{IgM}=0.712819825 \mathrm{C}_{3}+4.303343386 \mathrm{C}_{4}+1.132577042 \mathrm{IgA}+2.277364318 \bullet 10^{-1} \mathrm{IgG}$ \\
\hline 5 & $\mathrm{C}_{3}=3.585367208 \bullet 10^{-1} \mathrm{C}_{4}+6.713190408 \bullet 10^{-2} \mathrm{IgA}+7.353478958 \bullet 10^{-3} \mathrm{IgG}+8.940548152 \bullet 10^{-3} \mathrm{IgM}+1.139759762$ \\
\hline
\end{tabular}

\section{Discussion}

In the present work some of the authors pointed out about the food allergy may provoke migraine attack in the patients. We have tried to establishes the relation in the parameters by keeping one parameter as a constant. The immunological parameters are estimated and statistical formulae applied. Regression equations are also made and found that if one immunological parameter is fixed and others are changed. we have to stabilize the other parameters with the help of some modifications in the treatment, which may be given to the patients in the follow up the cases. All the measured levels of the different parameters are lower in comparison to the controls except IgG. Migraine problem is very difficult to rule out due to several factors related to the disease. on the basis of the statistical predictions some modifications are necessary in the management of the migraine.

\section{Acknowledgement}

One of the authors (sk) is thankful to Dr PK Gupta, Principal DAV College Muzaffarnagar, UP, India for providing necessary atmosphere to conduct the research.

\section{References}

1. Carlos HAM, Mauro EP, Herbert HML (2007) Food allergy mediated by IgG antibodies associated with migraine in adults. Revista, Alergia, Mexico, USA 54(5): 162-168.

2. Julio P, Agust'in O (2010) IgG-mediated allergy: A new mechanism for migraine attacks?. Cephalalgia 30(7): 777-779.

3. Mesut C, Sule B, Sedat M, Fikveri AK, sedat M (2012) Migraine and immuoglobulin E-mediated hypersensitivity/Migrenve immunoglobulinE aracili hipersensitivite. Arc of Neuro psychiatry 49(2): 129-132.

4. Pilarska E, Lemka M, Bakowska A (2006) Antiphospolipids antibodies in children with migraine ,Neurol. Neurochir 40(4): 291-296.

5. Shimomura T, Araga S, Kowa H, Takahashi K (2006) Immunoglobulin Kappa/lambda ratios in migraine and tension type headache. JPsychiatry Neurol 46(3): 721-726.

6. Balkan S, Muthu G, Kumudan A, Yagans S (1992) Immunoglobulin and complement levels in migraine. Mikrobiyal 20(4): 242-247.

7. Munno I, Marinaro M, Bassi A, Cassino M A, Causarano V, et al. (2001) Immunological aspects in migraine: increase of $1 \mathrm{~L}-10$ plasma levels during attack. Headache 41(8): 764-767.

8. Antani J, Andrzej K (1983) Immunoglobulins and omplemenet in migraine. Cephalalgia 3(2): 119-123.
9. Gazerani P, Pourpak Z, Ahmadiani A, Hemmati A, Kazemnejad A (2003) Correlation between migraine, histamine and immunoglobulin e 2(1): $17-24$.

10. Nattero G, Savi L, Allais G, Biale L (1984) Serum complemenets and immunoglobulins in patients with common migraine. Minerva, Med 75(20): 1185-1188.

11. Moore TL, Ryan RE Jr, Pohl DA, Roodman ST, Ryan RESr (2005) Immunoglobulin,complemenet,and immune complex levels during a migraine attack. The J of Head and face pain 20(1): 9-12.

12.12. DZugan SA, DZugan Konstantine S (2015) Is migrane a consequence of a loss of neurohormonal and metabolic integrity? A new hypothesis. Neuro endocrinology, Letters 36(5): 421-429.

13. Gauschino S, Spinillo A, Sances G, Martignami E (1985) Menstrual migraine old and new. Clin Exp Obstct Gynecol12: 67-71.

14. Sarrel P M (1990) Ovarian harmones and the circulation. Maturitas 12(3): 287-298.

15. Welch K M, Darnley D, Simkins R T (1984) The role of estrogen in migraine: a review and hypothesis. Cephalalgia 4(4): 277-286.

16. Diamond S, Wenzel R (2002) Practical approaches to migraine managemenet. CNS Drugs 16(6): 385-403.

17. Uzar E, Euliyaoglu O, Yucel Y, Ugurcevi K M , Acar A, et al. (2011) Serum cytokine and probrain natriuretic peptides (BNP)levels in patients with migraine. European. Review for Medical and Pharmacological Sciences 15(10): 1111-1116.

18. Tietjen G E (2009) Migraine as a systemic vasculopathy. CephalaLgia 29(9): 987-996.

19. Lord G D, Duckworth J W (1977) Immunoglobulin and complements studies in migraine. Headache The journal of Head and face pain 17(4): $163-168$.

20. Pascol J , Leno C (2005) A woman with daily headache. J Headache Pain 6: 91-92.

21. Merrett J, Peatfield R C, Clifford F R, Merrett TG (1983) Food related antibodies in headache patients. Journal of Neurology. Neurosurgery and Psychiatry 46(8): 738-742.

22. Arrovave Hernandez CM, Echavarria PM, Henandez Montiel HL (2007) Food allergy mediated by IgG antiodies associated with migraine in adults. Rev Alergy Mex 54(5): 162-168.

23. Rosario D, Pinto G (2014) Role of gender and serum immunoglobulin E (IgE) levels on severity of migraine. Journal of Clinical and Diagnostic Research 8(2): 57-58.

24. Aydinlar EI, Dikmen PY, Tiftikci A, Murat S, Muge A (2012) IgG-based elimination diet in migraine Plus iritative bowl syndrome. Headache: The Journal of Head and Face pain 53(3): 514-525.

25. Panconesi A,Bartolozzi ML, Guidi L (2009) Migraine Pain: Reflections against Vasodialation, Journal Headache Pain 10(5): 317-325. 
26. Yilmaz IA, Ozqe A, Erdal M E, Edgünlü TG, Cakmak SE, Yalin 00 (2010) Cytokine polymorphism in patients with migraine :Some suggestive clues of migraine and inflammation 11(4): 492-497.

27. Kurth T, Gaziano JM, Cook NR, Lagroscino G, Diener HC, Buring JCE (2006) Migraine and Cardiovascular disease in women. JAMA: 283-291.

28. Kurth T, schürks M, Lograscino G, GazianoJ M, Buring JE (2008) Migraine, vascular risk and cardiovascular events in women: Prospective cohort study. B Med J 337a636.
29. Scher Al, Terwindet GM, Picavet HS, Verschuren WM, Ferrari MD (2005) Cardiovascular risk factors and migraine: The GEM population baed study. Nerurology 64(4): 614-620.

30. Dålessio DJ (1990) The pathology of migraine. Clin JPain 6: 235-239.

31. Mancini G, Carbonara AO, Heremans JF (1965) Immunochemical quantitation of antigens by single radical immunodiffusion. Immunochemistry pp. 235-254.
(C) Commons Attribution 4.0 License

To Submit Your Article Click Here: Submit Article

DOI: $10.32474 /$ OAJBEB.2018.01.000114

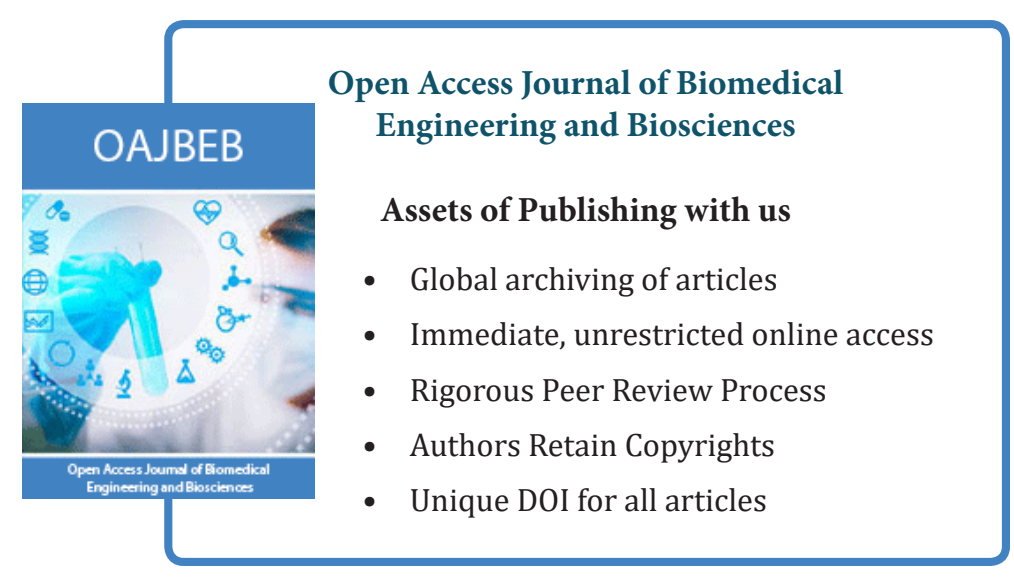

